
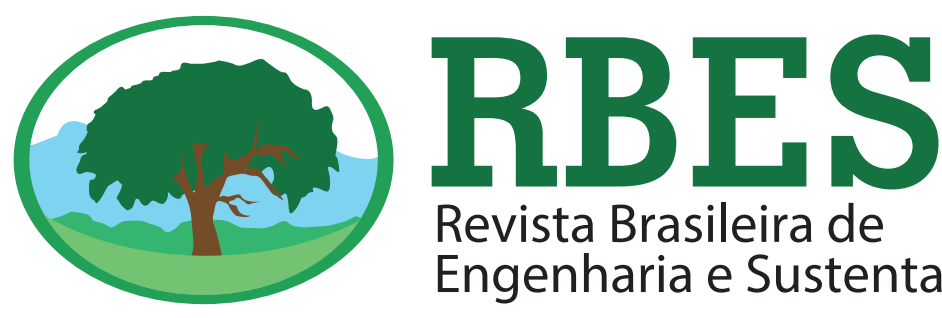

\title{
EFLUENTE DA PARBOILIZACÃO DE ARROZ COMO COSUBSTRATO EM BIODIGESTÃO ANAERÓBIA DÉ EFLUENTE DE LATICÍNIOS
}

NADALETIV, W. C. ', LOURENÇO, V. A. ${ }^{1}$, SCHOELER, G. P. ${ }^{1}$, LEANDRO, D. ${ }^{1}$, QUADRO, M. S. ${ }^{1}$

1 Universidade Federal de Pelotas, Centro de Engenharias.

Palavras-chave: Codigestão; biogás; biocombustível; lodo; inóculo.

\section{Resumo}

O Brasil é o um dos maiores produtores de laticínios do mundo, o setor gera de 2,5 e 4,0 $\mathrm{m}^{3}$ de efluente com alta concentração de gorduras para cada metro cúbico de leite processado. 0 emprego de um cosubstrato na biodigestão anaeróbia é capaz de promover a diluição de compostos inibitórios e, assim, elevar a produção de biogás. 0 efluente da indústria de arroz parboilizado é um possível cosubstrato para a biodigestão do efluente de laticínios, visto que não apresenta compostos inibitórios e é gerado em larga escala no país. 0 objetivo do estudo foi avaliar o uso desse efluente como cosubstrato para o processo de biodigestão anaeróbia do efluente da produção de laticínios, ambos gerados no município de Pelotas-RS. Os biodigestores operaram à $35^{\circ} \mathrm{C}$ em batelada, sendo que ao fim de 276 horas, a produção de biogás foi diretamente proporcional ao teor de cosubstrato na mistura, onde a maior proporção de efluente da parboilização de arroz produziu o maior volume de biogás, 3,39E-03 $\mathrm{m}^{3}$, e a biodigestão apenas do efluente da indústria de laticínios produziu 1,21E-03 $\mathrm{m}^{3}$, evidenciando que o efluente da parboilização de arroz apresenta resultados satisfatórios quando empregado como cosubstrato para a biodigestão anaeróbia do efluente da produção de laticínios.

\section{WASTEWATER OF RICE PARBOILING AS COSUBSTRATE IN ANAEROBIC BIODIGESTION OF DAIRY WASTEWATER}

Keywords: Codigestion; biogás; biofuel; sludge; inoculum.

\section{Abstract}

Brazil is one of the largest dairy producers in the world, the industry generates 2.5 to $4.0 \mathrm{~m}^{3}$ of wastewater with a high concentration of fats for each cubic meter of processed milk. The use of a cosubstrate in anaerobic biodigestion can promote the dilution of inhibitory compounds and, thus, increases biogas production. The wastewater from the parboiled rice industry is a possible cosubstrate for the anaerobic biodigestion of dairy wastewater, since it has no inhibitory compounds and is generated in large scale in the country. The objective of this study was to evaluate the use of this effluent as cosubstrate for the anaerobic biodigestion process of the effluent from dairy production, both generated in the city of Rio Grande do Sul. The biodigestors operated at $35^{\circ} \mathrm{C}$ in batch, and after 276 hours, the biogas production was directly proportional to the cosubstrate content in the mixture, where the highest proportion of rice parboiling wastewater produced the largest biogas volume, $3.39 \mathrm{E}-03 \mathrm{~m}^{3}$, and the biodigestion only of the wastewater from the dairy industry produced $1.21 \mathrm{E}-03 \mathrm{~m}^{3}$, evidencing that the wastewater from rice parboiling presents satisfactory results when used as a cosubstrate for the anaerobic biodigestion of effluent from dairy production. 


\section{INTRODUÇÃO}

A América do Sul produz cerca de 61,8 milhóes de toneladas de laticínios anualmente, tendo como principais produtores o Brasil, Colômbia e Peru (FAO, 2018). O setor é responsável por gerar de 2,5 a 4,0 litros de efluente para cada litro do produto (LEKSHMISREE; VIJAYAN, 2016; MURCIA et al., 2018), sendo o mesmo uma fonte poluidora constituída principalmente por matéria orgânica $(\mathrm{MO})$ (proteínas, gorduras e açúcares), microrganismos e nutrientes do leite derramado (KIRILOVA; BANCHEVA, 2017; MURCIA et al., 2018).

As características do efluente favorecem o uso de tratamentos biológicos, uma vez que 99\% de sua MO é biodegradável, entretanto, a gordura possui poder inibitório na atividade microbiológica (CASTRO et al., 2017; GOLUNSKI et al., 2017; HIROTA et al., 2016; KOTHARI et al., 2016). O processo de digestão anaeróbica é um tratamento biológico que produz biogás durante a degradação da matéria orgânica (GOLUNSKI et al., 2017; KOTHARI et al., 2016; YANG et al., 2017), a utilização de um cosubstrato no processo caracteriza uma codigestão anaeróbia (MARAGKAKI et al., 2017).

Nesse sentido, o efluente da indústria de arroz parboilizado surge como possível cosubstrato, uma vez que possui alto teor de $\mathrm{MO}$, não apresenta compostos inibitórios e é gerado em larga escala no país (BASTOS et al., 2010; KUMAR et al., 2016; QUEIROZ et al., 2007; SANTOS et al., 2012), de modo que seu potencial energético é capaz promover a autossuficiência energética do setor (NADALETI; PRZYBYLA, 2018).

O objetivo desse estudo foi avaliar o uso do efluente da indústria de arroz parboilizado como cosubstrato para elevar a eficiência do processo de biodigestáo anaeróbia do efluente da produção de laticínios, tendo em vista a diluição de sua gordura e, consequentemente, a possível queda de seu poder inibitório à ação dos microrganismos metanogênicos.

\section{MATERIAL E MÉTODOS}

Os biodigestores utilizados foram elaborados a partir da reutilização de garrafas de Politereftalato de Etileno (PET) de volume interno de $2,15 \mathrm{dm}^{3}$, revestidas com folhas finas de alumínio, de modo a impedir a incidência de luz, e vedadas com silicone acético incolor, garantindo que o fluxo dos gases fosse direcionado apenas para a saída responsável pelo seu transporte aos medidores.

A quantificação do biogás foi realizada através de medidores desenvolvidos com base no princípio de deslocamento de fluidos, sendo constituído em dois frascos comunicantes, um deles com escala volumétrica e conectado à parte superior do biodigestor (Figura 1). Tal conexão recebeu um divisor de ar, que quando aberto garante o escape do gás para atmosfera, acarretando no retorno do líquido à sua marca inicial, zerando o medidor. Os frascos conectados aos biodigestores receberam uma fina camada de óleo de soja acima da água, evitando a dissolução do $\mathrm{CO} 2$ contido no biogás no líquido.

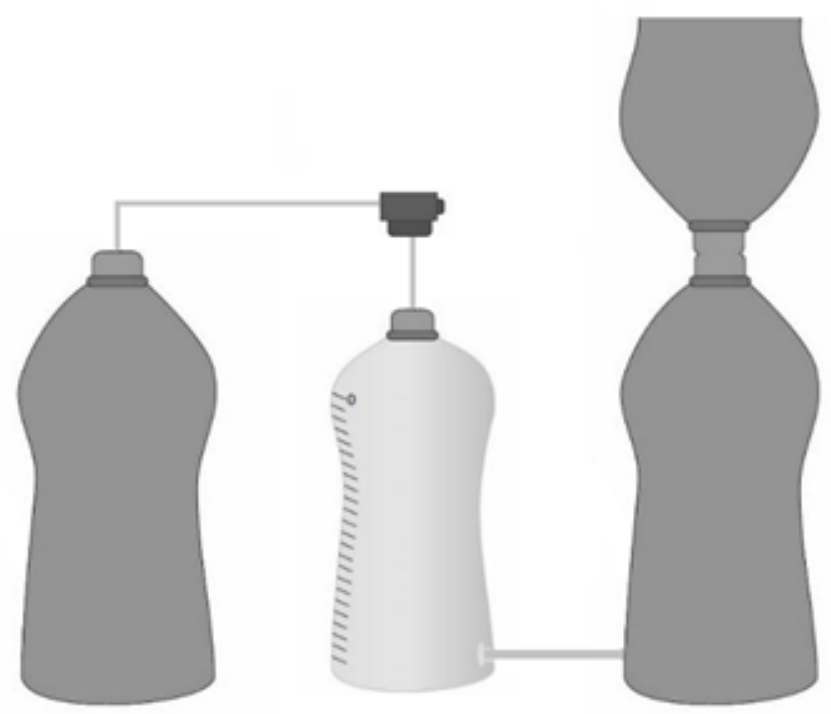

Figura 1. Esquema do sistema completo, biodigestor à esquerda e sistema de quantificação, frasco graduado ao centro e reservatório à direita.

Os biodigestores foram alocados em banho de aquecimento à $35^{\circ} \mathrm{C}$ e operados em batelada por um período de 276 horas, receberam como inóculo 3,00E$04 \mathrm{~m}^{3}$ de lodo retirado do UASB (Upflow Anaerobic Sludge Blanket) da estação de tratamento de efluentes de uma indústria de arroz parboilizado do município de Pelotas-RS, assim como o efluente bruto utilizado como cosubstrato. O efluente da indústria de laticínios foi retirado da estrada do UABS de uma indústria do setor, também situada no município de Pelotas.

Um dos processos foi alimentado com 1,40E-03 $\mathrm{m}^{3}$ de efluente da indústria de laticínios, outro com 
7,00E-04 $\mathrm{m}^{3}$ de cada um dos efluentes e um terceiro com 9,80E-04 $\mathrm{m}^{3}$ do efluente de arroz parboilizado e 4,20E-0 $4 \mathrm{~m}^{3}$ do efluente de laticínios (Figura 2), todos os processos foram executados em triplicatas.
Os volumes não preenchidos dos biodigestores funcionaram como headspace para armazenamento do gás gerado.

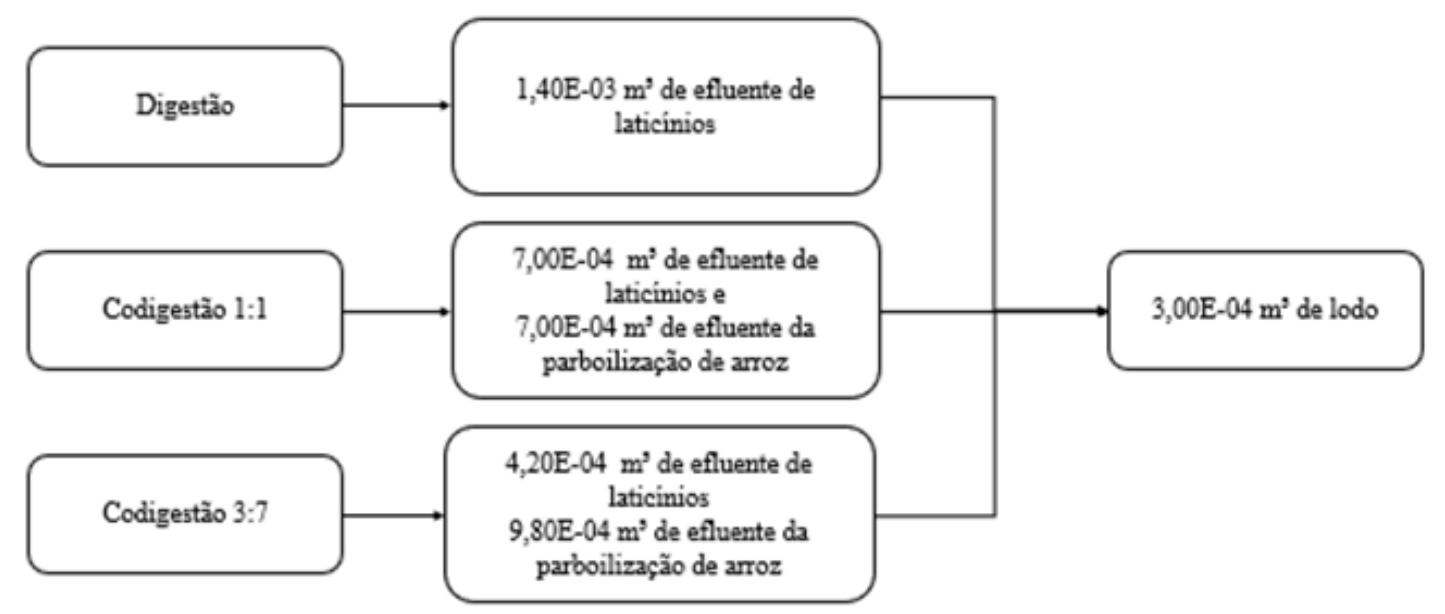

Figura 2 - Alimentação dos biodigestores.

A quantificação do biogás ocorreu diariamente valores superiores aos intervalos seguintes de 24 horas. em dois horários distintos, zerando-se o medidor em De acordo com a literatura, tal característica se dá ambos os momentos. As análises de Demanda Química de Oxigênio (DQO) e $\mathrm{pH}$ foram realizadas no Laboratório de Análise de Águas e Efluentes do Centro de Engenharias da Universidade Federal de Pelotas, de acordo com Standard Methods for the Examination of Water \& Wastewater (APHA; AWWA; WEF, 2005).

\section{RESULTADOS E DISCUSSÃO}

Como pode ser observado na Figura 3, todos os tratamentos apresentaram o pico de produção de biogás nas primeiras 12 horas de processo, com devido ao uso do lodo como inóculo do sistema, que é responsável pela antecipação da partida inicial na produção de biogás e do pico de produção, além da possibilidade de elevar o potencial efetivo da biomassa (CERRILlO; VIÑAS; BONMATÍ, 2017; LIU; SUN; SCÜNURER, 2017). A digestão, processo que recebeu apenas efluente da indústria de laticínios como substrato, apresentou menor pico, com 7,50E$05 \mathrm{~m}^{3}$ de biogás gerados nas primeiras 12 horas do experimento, enquanto a codigestâo $1: 1$ chegou a 2,42E-04 $\mathrm{m}^{3}$ e a 3:7 a 4,75E-04 $\mathrm{m}^{3}$.

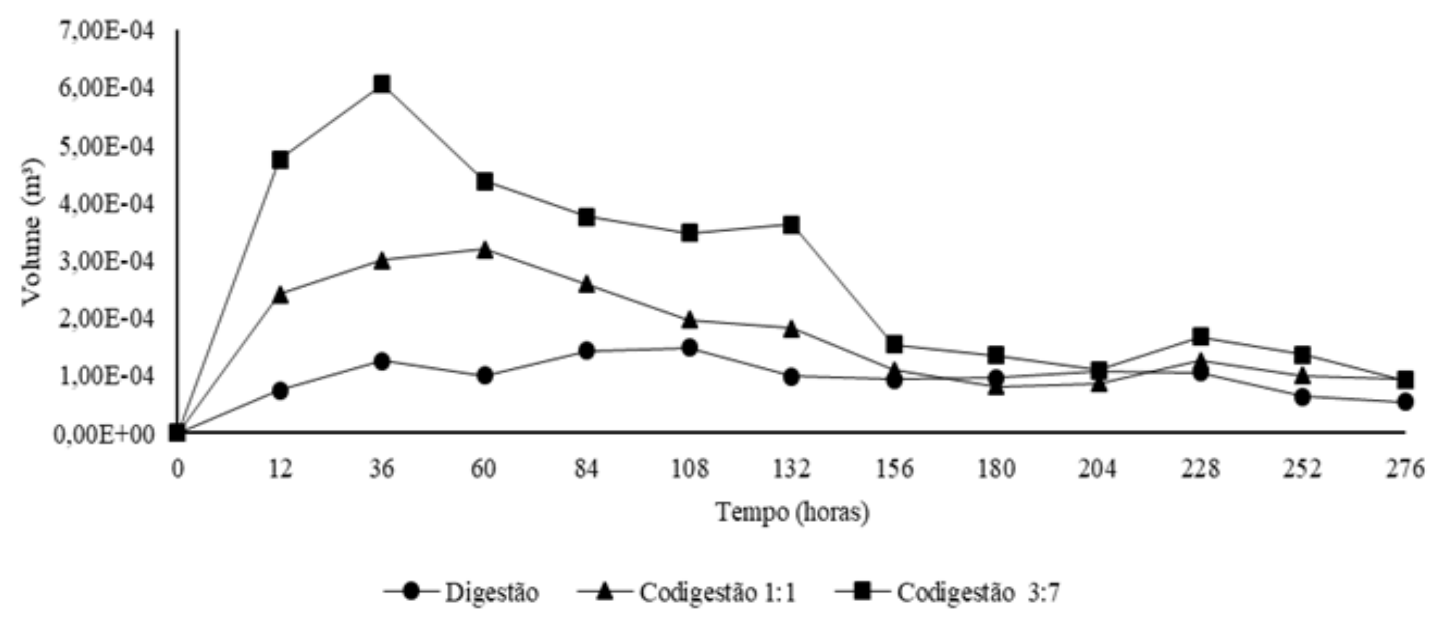

Figura 3. Gráfico da produção de biogás ao longo das 276 horas.

De acordo com a Figura 4, a produção total de diluição do substrato e, consequentemente, ao teor do biogás foi diretamente proporcional ao nível de cosubstrato adicionado na mistura: 


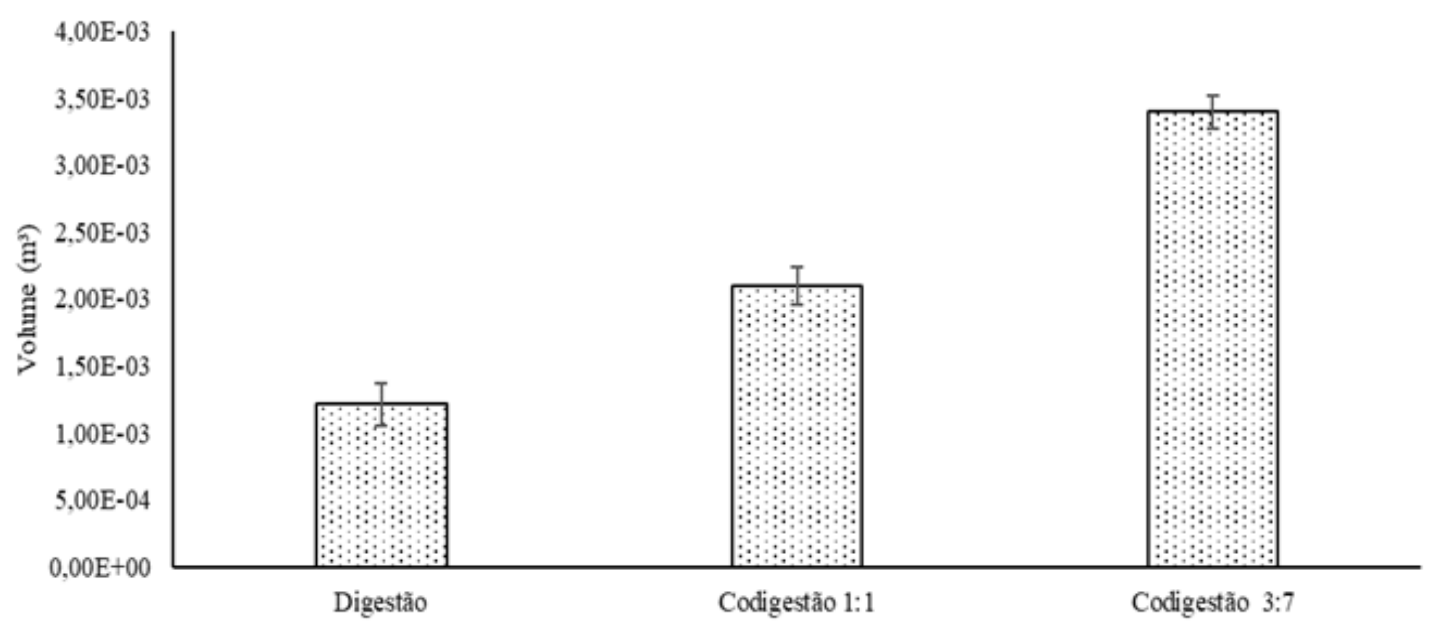

Figura 4. Gráfico da produção total de biogás em cada tratamento

A digestão apresentou a menor geração de biogás, como pode ser observado, totalizando uma geração de apenas 1,21E-03 $\mathrm{m}^{3}$. Dentre os processos de codigestáo, o que apresentou maior eficiência foi aquele que promoveu uma maior diluição do efluente de laticínios, codigestão 3:7, com uma produção de $3,39 \mathrm{E}-03 \mathrm{~m}^{3}$, enquanto a codigestão $1: 1$ apresentou uma geração de 2,09E-03 $\mathrm{m}^{3}$ de biogás, sendo que os resultados diferem estatisticamente pelo Teste de Tukey à $5 \%$ de significância. O sistema de quantificação apresentou baixo desvio padráo e coeficiente de variação, com máximas de 1,55E-04 $\mathrm{m}^{3}$ e $12,76 \%$ e mínimas de 1,27E-04 $\mathrm{m}^{3}$ e 3,74\%, respectivamente.

Ao considerar que parte da matéria orgânica do efluente de laticínios é constituída de gordura, que dificulta sua biodegradabilidade (HIROTA et al., 2016), torna-se compreensível seu baixo desempenho quando não associado ao cosubstrato. De acordo com Braun e Wellinger (2002) efluentes com propriedades dinâmicas pouco favoráveis ao serem associados a outros substratos podem ser mais facilmente degradados pelo processo de biodigestão anaeróbia.

As diferenças dos volumes de biogás gerados em cada processo também podem ser justificadas através DQO de entrada das misturas utilizadas na alimentação dos biodigestores, já que a DQO é comumente utilizada para estimar a matéria biodegradável convertida em biogás (NETO et al., 2017). A codigestão 3:7 apresentou uma DQO de entrada de superior à da digestão (Figura 5), assim como a codigestão 1:1, o que evidencia um maior teor de matéria orgânica no efluente da indústria de arroz parboilizado quando comparado com o da indústria de laticínios.

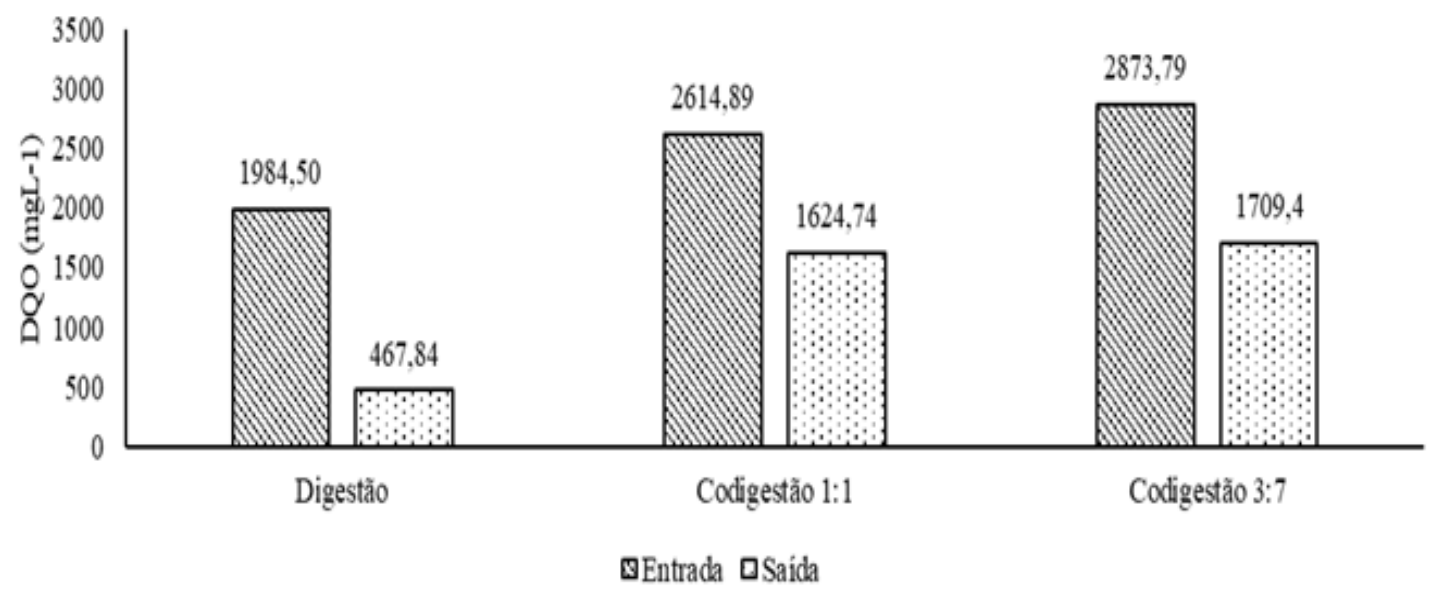

Figura 5. Gráfico da DQO de entrada e saída dos sistemas.

A maior taxa de remoção de DQO ocorreu na a eficiência de remoção de DQO de um sistema, digestão, 76,43\%, seguido das codigestôes 3:7 e 1:1, maior será a degradação dos substratos empregados com remoçôes de 40,52\% e 37,87\%, respectivamente. no processo, assim esperava-se que quanto maior a De acordo com Sgorlon et al. (2011) quanto maior remoção de DQO, maior seria a produção de biogás. 
Em estudo realizado por Macêdo et al. (2017) com efluente da indústria de laticínios com DQO 9582,80 $\mathrm{mg} / \mathrm{L}$ foi submetido ao processo de biodigestáo anaeróbia à $45^{\circ} \mathrm{C}$, em reatores de $2,0 \mathrm{E}-03 \mathrm{~m}^{3}$ de volume total, com 1,0E-03 $\mathrm{m}^{3}$ de headspace. Constatou-se baixa produtividade de metano $\left(\mathrm{CH}_{4}\right)$, ou seja, mesmo com a alta DQO apresentada pelo substrato ocorreu inibição da atividade metanogênica. Estudos realizados por Nadaleti et al. (2018) acerca da produção de biogás via biodigestáo anaeróbia de efluente da parboilização do arroz, em biodigestores semelhantes aos utilizados neste estudo, foi constada uma produção de 5,2E-03 $\mathrm{m}^{3}$ de biogás em um período de 276 horas quando operados à $35^{\circ} \mathrm{C}$, evidenciando que o efluente possui alto potencial de produção de biogás.

Todas as amostras de saída dos biodigestores apontaram para a ocorrência da neutralização das misturas após os processos de biodigestão anaeróbia (Figura 6):

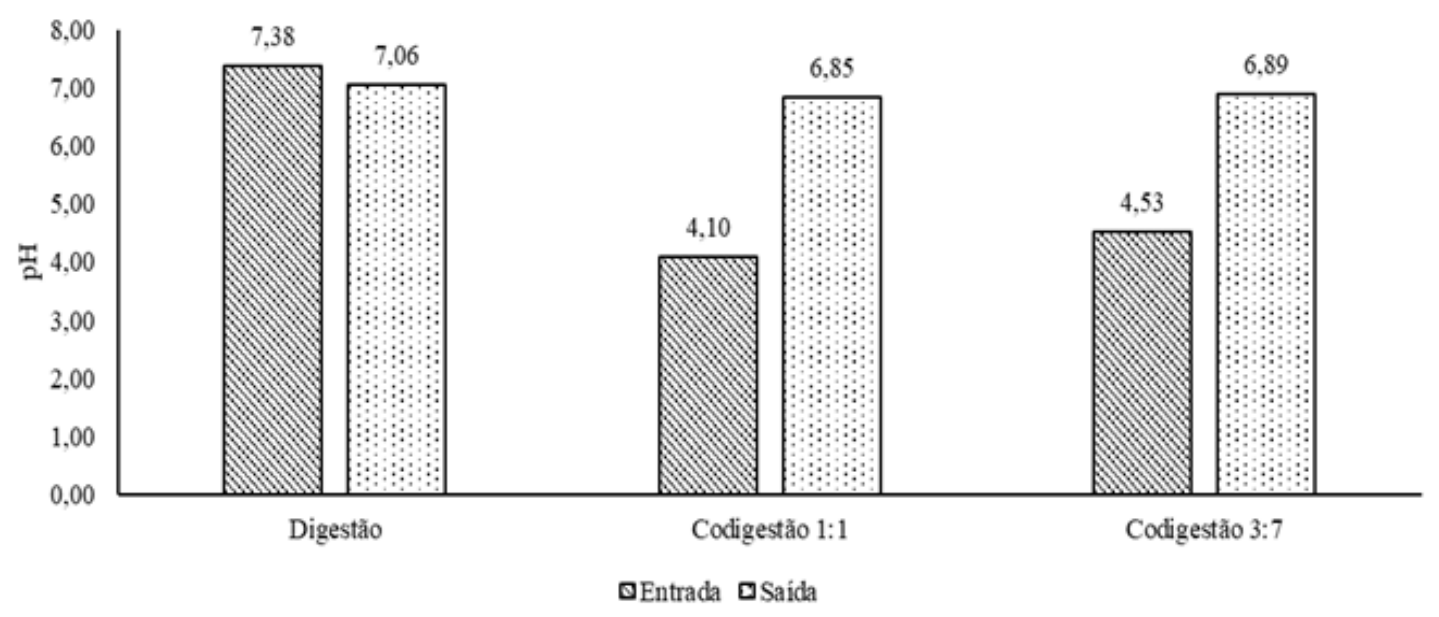

Figura 6. Gráfico do pH de entrada e saída dos sistemas.

Quando o sistema apresenta população de bactérias metanogênicas suficiente e em condiçôes favoráveis o $\mathrm{pH}$ tende a permanecer neutro durante todo o processo de biodigestão anaeróbia (GUERI; SOUZA.; KUCZMAN, 2018), como ocorreu no processo de digestão do efluente de laticínios. Esse parâmetro também direciona a baixa produção de biogás à presença de gordura no efluente de laticínios, já que o processo que recebeu apenas este efluente foi o único a apresentar $\mathrm{pH}$ de entrada neutro, sendo este o mais favorável para a produção do gás, entre 6,7 e 7,5, onde ocorre o crescimento da maioria das bactérias metanogênicas (MANONMANI et al., 2017), e ainda assim foi o que obteve desempenho inferior aos demais.

\section{CONCLUSÃO}

1. O efluente da indústria de arroz parboilizado apresentou resultado satisfatório nesse estudo quando empregado como cosubstrato para a biodigestáo anaeróbia do efluente da produção de laticínios para a produção de biogás;

2. O processo de codigestão dos substratos foi capaz de elevar a produção de biogás em até 179,37\% em relação ao processo que recebeu apenas o efluente da indústria de laticínios como substrato;

3. Dentre as codigestóes executadas no estudo, a mistura de 3:7 de efluente da indústria de laticínios em relação ao efluente da parboilização de arroz, foi a que apresentou maior produção de biogás durante as 276 horas, totalizando $3,39 \mathrm{E}-03 \mathrm{~m}^{3}$.

\section{LITERATURA CITADA}

AMERICAN PUBLIC HEALTH ASSOCIATION
$\begin{array}{lll}\text { (APHA), AMERICAN WATER } & \text { WORKS } \\ \text { ASSOCIATION } & \text { (AWWA) \& } & \text { WATER } \\ \text { ENVIRONMENT } & \text { FEDERATION } & \text { (WEF). }\end{array}$

Standard Methods for the Examination of Water and Wastewater. Method 5220-C, p. 5-16, 2005; Introduction 4500-N A, p.4-103, 2005.

BASTOS, R. G.; SEVERO, M.; VOLPATO, G.; JACOB-LOPES, E.; ZEPKA, L. Q.; QUEIROZ, M. I. Bioconversão do nitrogênio do efluente da parboilizaçáo do arroz por incorporação em biomassa 
da cianobactéria Aphanothece microscopica Nägeli. Revista Ambiente e Água, v.5, n.3, 2010.

BRAUN, R.; WELLINGER, A. Potential of CoDigestion. IEA Bioenergy, Task 37 - Energy from biogas and landfill gas, 2002.

CASTRO, G. M.; SCHWANTES, D.; JUNIOR, A. C. G.; RICHART, A.; VEIGA, T. G.; ROSENBERGER, A. G. Treatment of dairy effluents in wetlands systems with floating aquatic macrophytes. Revista de Ciências Ambientais, v.11, n.2, p.25-37, 2017.

CERRILLO, M.; VIÑAS, M.; BONMATÍ, A. Startup of electromethanogenic microbial electrolysis cells with two diferent biomass inocula for biogas upgrading. ACS Sustainable Chemistry \& Engineering. v.5, n.10, p.8852-8859, 2017.

FAO. Food and Agriculture Organization of the United Nations. Dairy Market Review - Milk production trends in 2017. April 2018. Disponível em:< http:// www.fao.org/3/I9210EN/i9210en.pdf>. Acesso em: 24 de abr. de 2018.

GOLUNSKI, S. M.; MULINARI, J.; CAMARGO, A. F.; VENTURIN, B.; BALDISSARELLI, D. P.; MARQUES, C. T.; VARGAS, G. D. L. P.; COLLA, L. M.; MOSSI, A.; TREICHEL, H. Ultrasound effects on the activity of Aspergillus Niger lipases in their application in dairy wastewater treatment. Environ QualManage, v. 27, n.1, p.95-101, 2017.

GUERI, M. V. D.; SOUZA, S. N. M.; KUCZMAN, O. Parâmetros operacionais do processo de digestão anaeróbia de resíduos alimentares: uma revisão. BIOFIX Scientific Journal, v.3, n.1, p. 17-25, 2018.

HIROTA, K.; YOKATA, Y.; SEKIMURA, T; UCHIUMI, H.; GUO, Y.; OHTA, H.; YUMOTO, I. Bacterial communities in different locations, seasons and segments of a dairy wastewater treatment system consisting of six segments. Journal of Environmental Sciences, v.36, p.109-115, 2016.
KIRILOVA, E. G.; VAKLIEVA-BANCHEVA, N. G. Environmentally friendly management of dairy supply chain for designing a green products' portfolio. Journal of Cleaner Production, v.167, p.493-504, 2017.

KOTHARI, R.; KUMAR, V.; PATHAK, V. V.; TYAGI, V. V. Sequential hydrogen and methane production with simultaneous treatment of dairy industry wastewater: Bioenergy profit approach. International Journal of Hydrogen Energy, v.42, n.8, p.4870-4879, 2017.

KUCZMAN, O.; GUERI, M. V. D.; SOUZA, S. N. M.; SCHIRMER, W. N.; ALVES. H. J.; SECCO, D.; BURATTO, W. G.; RIBEIRO, C. B.; HERNANDES, F. B. Food waste anaerobic digestion of a popular restaurant in Southern Brazil. Journal of Cleaner Production, v.196, p.382-289, 2018.

KUMAR, A.; ROY, A.; PRIYADARSHINEE, R.; SENGUPTA, B.; MALAVIYA, A.; DASGUPTAMANDAL, D.; MANDAL, T. Economic and sustainable management of wastes from rice industry: combating the potential threats.

Environmental Science and Pollution Research, v.24, n.34, p.26279-26296, 2017.

LEKSHMISREE, A.S; VIJAYAN, N. Treatment of Dairy Industry Waste Water Using Fungal Consortium. International Research Journal of Engineering and Technology (IRJET), v.3, n.8, p.1924-1929, 2016.

LIU, T.; SUN, L.; SCÜNURER, B. M. A. Importance of inoculum source and initial community structure for biogas production from agricultural substrates. Bioresource Technology, v. 245, part A, p.768-777, 2017.

MACÊDO, W. V.; VALENÇA, R. M.; AMORIM, E. L. C. Produção de biohidrogénio a partir de efluentes de laticínios, lactose isolada e soro de queijo em reatores anaeróbios em batelada em temperatura termofílica. Revista Brasileira de Energias Renováveis, v.6, n.2, p.260-273, 2017. 
MANONMANI, P.; MUAZU, L.; KAMARAJ, M. C.; GOEL, M.; ELANGOMATHAVAN, R. Biogas production potential of food waste. International Journal of Environment Agriculture and Biotechnology, v. 2, n. 2, p. 707-711, 2017.

MARAGKAKI, A. E.; FOUNTOULAKIS, M.; GYPAKIS, A.; KYRIAKOU, A.; LASARIDI, K.; MANIOS, T. Pilot-scale anaerobic co-digestion of sewage sludge with agro-industrial by-products for increased biogas production of existing digesters at wastewater treatment plants. Waste Management, v.59, p.362-370, 2017.

MURCIA, J. J.; HERNÁNDEZ-LAVERDE, M.; ROJAS, H.; MUÑOZ, E.; NAVÍO, J. A.; HIDALGO, M. C. Study of the effectiveness of the flocculationphotocatalysis in the treatment of wastewater coming from dairy industries. Journal of Photochemistry and Photobiology A: Chemistry, v.358, p.256-264, 2018.

NADALETI, W. C.; LOURENÇO, V. A.; SCHOELER, G. P.; AFONSO, M; SANTOS, R. F.; VIEIRA, B. M.; LEANDRO, D.; QUADRO, M. S. Temperaturas mesófilas e termófilas na produção de Biogás através de efluente da parboilização do arroz. Revista Brasileira de Engenharia e Sustentabilidade, v.5, n.1, p.17-21, 2018.

NADALETI, W. C.; PRZYBYLA, G. Emissions and performance of a spark-ignition gas engine generator operating with hydrogen-rich syngas, methane and biogas blends for application in southern Brazilian rice industries. Energy, v.154, p.38-51, 2018.

NETO, J. G.; SILVA, J. D.; PINHEIRO, I. G. Balanço de massa no tratamento de resíduos sólidos orgânicos provenientes de restaurantes em biorreator. Revista Engenharia Sanitária e Ambiental, v.22, n. 3, 2017.

QUEIROZ, M. I.; LOPES, E. J.; ZEPKA, L. Q.; BASTOS, R. G.; GOLDBECK, R. The kinetics of the removal of nitrogen and organic matter from parboiled rice effluent by cyanobacteria in a stirred batch reactor.
Bioresource Technology, v.98, p.2163-2169, 2007.

SANTOS, D. G.; TURNES, C. G.; CONCEIÇÃO, F. R. Bioremediation of Parboiled Rice Effluent Supplemented with Biodiesel-Derived Glycerol Using Pichia pastoris X-33. Scientific World Journal, 2012.

Disponível em:<https://www.ncbi.nlm.nih.gov/pmc/ articles/PMC3417191/\#B1>. Acesso em: 29 mar. 2018.

SGORLON, J. G.; RIZK, M. C.; BERGAMASCO, R.; TAVARES, C. R. G. Avaliação da DQO e da relação $\mathrm{C} / \mathrm{N}$ obtidas no tratamento anaeróbio de resíduos fruti-hortículas. Acta Scientiarum Technology, v.33, n.4, p.421-424, 2011.

YANG, S.; PHAN, H. V.; BUSTAMANTE, H.; GUO W.; NGO, H. H.; NGHIEM, L. D. Effects of shearing on biogas production and microbial community structure during anaerobic digestion with recuperative thickening. Bioresource Technology, v.234, p.439-447, 2017. 